\title{
Overexpression of GRK6 associates with the progression and prognosis of colorectal carcinoma
}

\author{
RAN TAO ${ }^{1^{*}},{\text { QIANG } \mathrm{LI}^{2 *}, \text { XIAOFEI GAO }}^{3^{*}}$ and LILIN MA 1* $^{*}$ \\ ${ }^{1}$ Department of General Surgery, Affiliated Hospital of Nantong University, Nantong, Jiangsu 226001; \\ ${ }^{2}$ Department of General Surgery, The Second Affiliated Hospital of Xuzhou Medical University, Xuzhou, Jiangsu 221000; \\ ${ }^{3}$ Department of Cardiology, The First People's Hospital of Hangzhou, Hangzhou, Zhejiang 310000, P.R. China
}

Received November 23, 2016; Accepted January 10, 2018

DOI: $10.3892 / \mathrm{ol} .2018 .8030$

\begin{abstract}
There are a limited number of studies reporting on the expression of $\mathrm{G}$ protein-coupled receptor kinase 6 (GRK6) in colorectal carcinoma (CRC). The aim of the present study was to investigate and examine the clinical value of GRK6 expression in human CRC. The expression of the GRK6 protein was determined in CRC tissues $(n=83)$ and in normal colorectal tissues $(n=19)$ by immunohistochemical (IHC) analysis. In addition, reverse transcription-quantitative polymerase chain reaction (RT-qPCR) was conducted to investigate GRK6 mRNA levels in matched pairs of cancerous and non-cancerous fresh frozen tissues from 19 patients with CRC. Furthermore, GRK6 protein levels were evaluated in matched pairs of cancerous and non-cancerous fresh frozen tissues from 19 other patients with CRC by western blot analysis. The expression of GRK6 was significantly upregulated in patients with CRC as indicated by IHC analysis $(\mathrm{P}=0.028)$. The results of RT-qPCR and western blotting confirmed that GRK6 mRNA and protein levels were upregulated in CRC tissues compared with matched adjacent non-cancerous tissues $(\mathrm{P}<0.05)$. Additionally, GRK6 protein expression was significantly associated with histological differentiation $(\mathrm{P}=0.001)$, lymph node invasion $(\mathrm{P}=0.45)$, venous invasion $(\mathrm{P}=0.009)$, depth of invasion $(\mathrm{P}=0.026)$, distant metastasis $(\mathrm{P}<0.0001)$ and TNM stages $(\mathrm{P}=0.020)$. Survival analysis using the Kaplan-Meier method indicated that patients with high GRK6 expression levels exhibited lower overall survival rates compared with patients with low GRK6 expression. Multivariate analysis using the Cox proportional
\end{abstract}

Correspondence to: Dr Lilin Ma, Department of General Surgery, Affiliated Hospital of Nantong University, 20 Xisi Road, Congchuan, Nantong, Jiangsu 226001, P.R. China

E-mail: 295090103@qq.com

${ }^{*}$ Contributed equally

Key words: G protein-coupled receptor kinase 6, overexpression, prognosis, western blotting, reverse transcription-quantitative polymerase chain reaction, immunohistochemistry, colorectal cancer hazards model indicated that the expression levels of GRK6 $(\mathrm{P}=0.003)$ were independent prognostic factors for overall survival in patients. The overexpression of GRK6 in patients with CRC may serve as an independent predictor of patient outcome.

\section{Introduction}

Colorectal carcinoma (CRC) is the third most common type of cancer worldwide, which accounts for $10 \%$ of all tumors $(1,2)$. In previous years, the incidence of CRC has increased yearly, which can be attributed to changes in lifestyle, diet and deteriorating environmental factors. Despite the advances made in the prevention and treatment of $\mathrm{CRC}$, the 5-year survival rate of patients is $35 \%$ in most regions of the world (3-5). Recent investigations have revealed that the incidence, progression, invasion and metastases of CRC result from the interaction of multiple genes and factors (6-8). Even after undergoing curative surgery, a substantial proportion of patients with CRCs, experience tumor recurrence $(2,9)$. Despite the current advancements in molecular biology, few of these techniques have been introduced into clinical practice for treatment. The aim of the present study was to identify a potential biomarker that may predict the prognoses of patients with CRC.

The $\mathrm{G}$ protein-coupled receptor kinases (GRKs) are a versatile family of kinases, which serve a critical role in $G$ protein-coupled receptor homologous desensitization. GRKs promote the receptor-arrestin interaction and the uncoupling of the receptor from its $\mathrm{G}$ protein, by phosphorylating specific serine and threonine residues in the cytoplasmic domains of the activated receptor $(10,11)$. Despite the critical role of GRKs in homologous desensitization, aberrant GRK activity has been identified in cases of opiate addiction, heart failure, and tumor progression and metastasis (12-14). Therefore, GRKs are hypothesized to be valuable therapeutic targets. GRK6, a member of the GRK family, is present in many human tissues, and has been implicated in multiple disease pathways $(15,16)$. Additionally, present studies indicate that GRK6 may be implicated in the metastasis of several carcinomas, including hepatic and lung cancer, medulloblastoma and multiple myelomas (17-19). However, the prognostic value and the clinicopathological significance of GRK6 in CRC have not been previously reported. 
The purpose of the present study was to investigate GRK6 expression and evaluate the clinicopathological features in patients with CRC and to investigate the potential association of GRK6 in the origin and progression of CRC.

\section{Materials and methods}

The reporting of the present study was in accordance with the REMARK guidelines (20).

Tissue specimens and clinicopathological data. A total of 83 patients with CRC were enrolled in the present study at the Affiliated Hospital of Nantong University (Nantong, China) from March 2009 to February 2010. A total of 39 females and 44 males were included in the present study, ranging from 25-65 years, with a mean age of 57 years. Specimens of tumor tissues and adjacent paracancerous histological normal tissues (PCHNTs) were collected during surgery. The PCHNT specimens were extracted $>3 \mathrm{~cm}$ from the tumor margin and assessed microscopically for the presence of normal cells and the absence of dysplastic cells. Following surgical removal, the fresh specimens were divided into two equal halves. One half was fixed in formalin, embedded in paraffin, and used for immunohistochemical staining. The other half was preserved at $-80^{\circ} \mathrm{C}$ after freezing in liquid nitrogen for further analysis by western blotting and RT-qPCR. Clinicopathological data were obtained, and the tumor-node-metastasis (TNM) stages and lymph node status were determined. The stages and grades of tumors were determined according to the criteria listed in the fifth edition of TNM classification of the International Union Against Cancer (21). None of the patients with CRC had received preoperative radiotherapy or chemotherapy prior to surgery. Following surgery, all patients received standard treatments according to the National Comprehensive Cancer Network guidelines (22). The present study was approved by the Ethics Committee of the Affiliated Hospital of Nantong University. All experiments were performed in accordance with the approved guidelines of the Affiliated Hospital of Nantong University and the 1964 Helsinki Declaration and its later amendments. Written informed consent was obtained from all participants prior to undergoing surgery.

Immunohistochemistry analysis. The paraffin-embedded tissue sections $(\sim 2 \mathrm{~mm})$, were dewaxed in xylene, rehydrated in a series of ethanol (70\% for $30 \mathrm{~min}, 80 \%$ for $60 \mathrm{~min}, 90 \%$ for $60 \mathrm{~min}, 95 \%$ for $60 \mathrm{~min}, 95 \%$ for $60 \mathrm{~min}, 100 \%$ for $60 \mathrm{~min}$ and $100 \%$ for $60 \mathrm{~min}$ ) and immersed in 3\% hydrogen peroxide at room temperature for $5 \mathrm{~min}$ to suppress the endogenous peroxidase activity. The tissues sections were heated at $100^{\circ} \mathrm{C}$ for $10 \mathrm{~min}$ in $0.01 \mathrm{~mol} / 1$ sodium citrate buffer (pH 6.0) to facilitate antigen retrieval. After three washes with phosphate-buffered saline (PBS) for $5 \mathrm{~min}$ each, the sections were incubated at room temperature for $2 \mathrm{~h}$ with a polyclonal rabbit anti-human GRK6 primary antibody (cat. no. sc-566; 1:200; Abcam, Cambridge, UK) diluted in PBS. The anti-GRK6 monoclonal antibody was used to determine the expression of the GRK6 protein. The sections were washed three times in PBS for 5 min each, and incubated with a HRP-conjugated goat anti-rabbit secondary immunoglobulin G (cat. no. SA00004-6; 1:200; ProteinTech Group, Inc., Chicago, IL, USA) for $1 \mathrm{~h}$ at room temperature. After three additional washes with PBS, the antigen-antibody complexes were developed with diaminobenzidine (DAB, $20 \mu \mathrm{l}+\mathrm{PBS}, 1,000 \mu \mathrm{l}+3 \% \mathrm{H}_{2} \mathrm{O}_{2}, 5 \mu \mathrm{l}$ ) staining at room temperature for $10 \mathrm{~min}$.

A total of three observers determined the immunohistochemical staining scores (ISS), which is based on staining frequency and intensity. Staining frequency was scored as follows: No staining was scored as $0 ; 1-25 \%$ of stained cells was scored as $1 ; 25-50 \%$, as $2 ; 51-75 \%$, as 3 ; and $>75 \%$, as 4 . Staining intensity was rated on a scale of $0-3$ as follows: 0 , negative; 1 , weak; 2 , moderate; and 3 , strong. The raw data were converted into ISS by multiplying the corresponding frequency scores and the staining intensity scores. Therefore, the ISS could range from 0 to 12 . An ISS of 9-12 was designated as strong immunoreactivity $(+++) ; 5-8$, as moderate $(++) ; 1-4$, as weak $(+)$; and 0 , as negative (-) immunoreactivity. The sections with staining in the cell cytoplasm of $>25 \%$ tumor cells were deemed as positive for GRK6. Staining was scored independently by three individuals. Based on the results of immunohistochemical staining for GRK6 expression, patients with CRC were divided into two groups, one with low GRK6 expression (- to + ) and another with high GRK6 expression (++ to +++).

Western blot analysis. Total protein was extracted using a lysis buffer (Thermo Fisher Scientific, Inc., Waltham, MA, USA) that contains protease inhibitors. A total of $30 \mu \mathrm{g}$ of protein were separated by $10 \%$ SDS-PAGE gel electrophoresis and transferred to polyvinylidene fluoride (PVDF) membranes. Non-specific binding was blocked by incubating the membranes with 5\% non-fat milk in Tris-buffered saline containing $0.1 \%$ Tween-20 (TBST) for $2 \mathrm{~h}$ at room temperature. Following incubation with the polyclonal rabbit anti-human GRK6 antibody (dilution 1:1,000; cat. no. sc-566; Abcam), or rabbit anti-GAPDH antibody (dilution 1:2,000; cat. no. SAB2701826; Sigma-Aldrich; Merck KGaA, Darmstadt, Germany), overnight at $4^{\circ} \mathrm{C}$, the membranes were washed three times with TBST for $5 \mathrm{~min}$. The membranes were then incubated with horseradish peroxidase-conjugated goat anti-rabbit secondary antibody (dilution 1:1,000; Sigma-Aldrich; Merck KGaA) at room temperature for $2 \mathrm{~h}$. The signals were detected using enhanced chemiluminescence (GE Healthcare, Chicago, IL, USA) followed by film development.

In addition, 19 other pairs of samples of cancerous tissues and matched non-cancerous fresh frozen tissues were collected for reverse transcription-quantitative polymerase chain reaction (RT-qPCR) analysis. Similarly, western blot analysis was performed on 19 other pairs of cancerous tissues and matched non-cancerous fresh frozen tissues, by the aforementioned method.

$R T-q P C R$. GRK6 mRNA expression was analyzed by RT-qPCR (23). Total RNA was extracted using TRIzol ${ }^{\circledR}$ reagent (Gibco; Thermo Fisher Scientific, Inc.) according to the manufacturer's instructions from the CRC tissues. Reverse transcription was performed at $42^{\circ} \mathrm{C}$ for $60 \mathrm{~min}$ followed by $70^{\circ} \mathrm{C}$ for 5 min using the Transcriptor First Strand cDNA Synthesis kit (Roche Diagnostics GmbH, Mannheim, Germany). RT-qPCR was performed using FastStart Universal SYBR-Green Master (Rox; Roche Diagnostics GmbH). According to the protocol, $2 \mu \mathrm{l}$ cDNA was added to a $20 \mu \mathrm{l}$ final reaction volume. The RT-qPCR analysis was performed in 96-well plates in a 

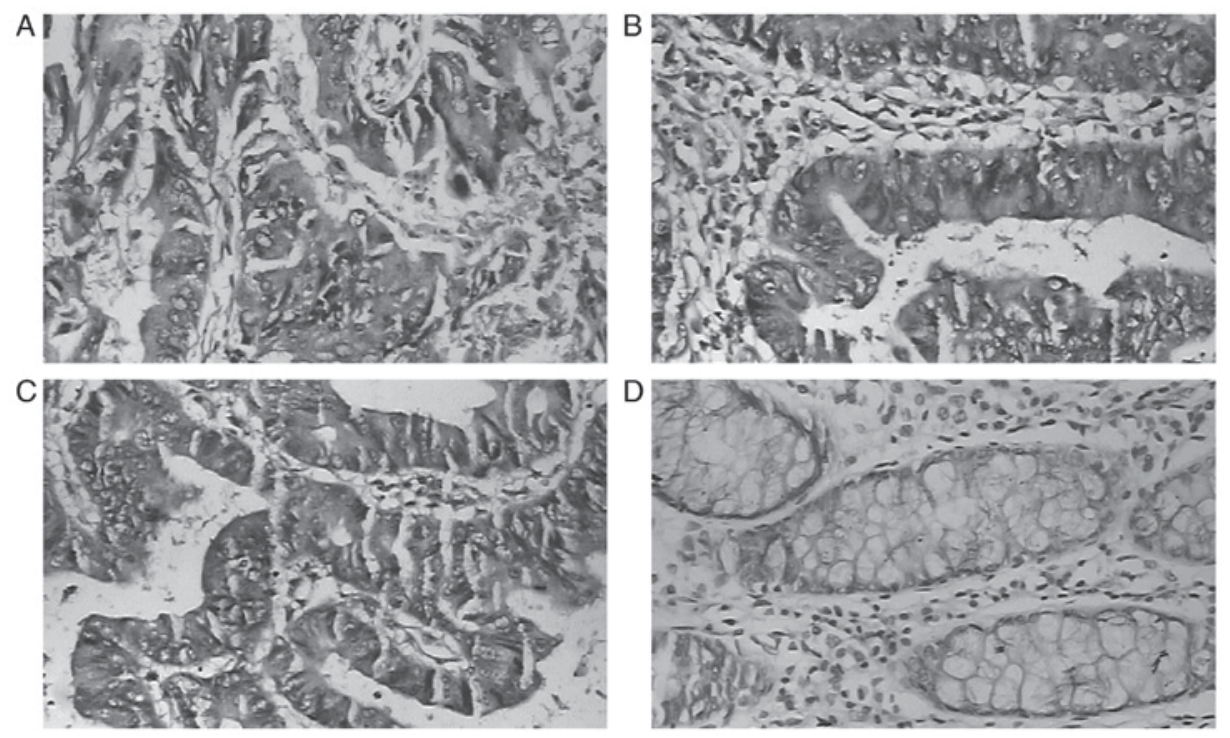

Figure 1. Immunohistochemical staining of GRK6 in CRC tissues, corresponding PCHNTs and normal colorectal tissues. (A) Strongly positive and (B) positive GRK6 expression in CRC tissues; (C) weakly positive expression in PCHNTs; (D) negative GRK6 expression in normal colorectal tissues. CRC, colorectal carcinoma; GRK6, G protein-coupled receptor kinase 6; PCHNT, paracancerous histological normal tissue.

thermocycler (ABI Prism 7500; Applied Biosystems; Thermo Fisher Scientific, Inc.). The cycling parameters used were as follows: Hot start at $95^{\circ} \mathrm{C}$ for $10 \mathrm{~min}, 40$ cycles of amplification, quantification at $95^{\circ} \mathrm{C}$ for $15 \mathrm{sec}$, and $57^{\circ} \mathrm{C}$ for $1 \mathrm{~min}$, during which time fluorescence was measured, at $72^{\circ} \mathrm{C}$ for $30 \mathrm{sec}$. Continuous fluorescence acquisition was performed at $65-97^{\circ} \mathrm{C}$ in order to perform melting curve analysis. These cycling parameters generated a single amplification for the primer set used, according to the presence of a single melt peak. GAPDH was selected as the internal reference. All RT-qPCR reactions were repeated 3 times for each gene, and each sample was set up in triplicate. Primer sequences were designed based on published human gene sequences. The primer sequences were as follows: GRK6 forward primer, 5'-AAAACACCTTCAGGC AATACCG-3'; and reverse primer, 5'-AGGCCAAGCTCACTA CAAACCTA-3'. GAPDH forward primer, 5'-CATGAGAAG TATGACAACAGCCT-3'; and GAPDH reverse primer, 5'-AGT CCTTCCACGATACCAAAGT-3'. The $2^{-\Delta \Delta C q}$ method was used to calculate relative changes in gene expression (24).

Statistical analysis. SPSS statistical software (version 17.0; SPSS Inc., Chicago, IL, USA) was used for data analyses. The GRK6 mRNA levels in CRC and PCHNT specimens were compared using the paired Student's t-test. Student's t-test for independent samples was performed to compare the means of two groups. The $\chi^{2}$ test was used to determine the significance of GRK6 expression and the clinicopathological variables of CRC. Kaplan-Meier analysis was used to compute survival rates, and statistical significance was assessed by using the log-rank test. A univariate analysis with the Cox regression model was used to determine the identified prognostic factors, and multivariate analysis with the Cox regression model was used to investigate the combined effects. Spearman's rank correlation analysis was used to analysis the association between GRK6 expression and TNM stage in colorectal carcinoma. The results are presented as mean \pm standard deviation of a minimum of three independent experiments. $\mathrm{P}<0.05$ was
Table I. GRK6 expression in CRC, PCHNT and normal colorectal tissues.

\begin{tabular}{lrrrrrr}
\hline \multirow{2}{*}{$\begin{array}{l}\text { Clinical } \\
\text { parameters }\end{array}$} & & \multicolumn{4}{c}{ GRK6 expression } & \\
\cline { 3 - 6 } & $\mathrm{n}$ & - & + & ++ & +++ & $\begin{array}{c}\text { Positive } \\
\text { rate (\%) }\end{array}$ \\
\hline CRC & 83 & 13 & 37 & 22 & 11 & 84.3 \\
PCHNT & 83 & 73 & 7 & 3 & 0 & 12.0 \\
Normal tissue & 19 & 17 & 2 & 0 & 0 & 10.5 \\
\hline
\end{tabular}

CRC vs. PCHNT, $\mathrm{P}<0.0001$; $\mathrm{CRC}$ vs. normal tissue, $\mathrm{P}=0.028$; PCHNT vs. normal tissue, $\mathrm{P}=0.289$. GRK6, G protein-coupled receptor kinase 6; CRC, colorectal carcinoma; PCHNT, paracancerous histological normal tissue.

considered to indicate a statistically significant difference (25). Furthermore, the survival rates of patients based on GRK6 positivity were analyzed by separating the patients into two groups based on the stage of disease: I-II and III-IV.

\section{Results}

Upregulation of GRK6 expression in primary colorectal tumors. The results of the immunohistochemical analysis demonstrated that GRK6 expression was significantly increased in patients with CRC compared with normal CRC tissues (Fig. 1). GRK6 expression was observed in 70 of 83 patients with CRC (84.3\%); 33 patients demonstrated strong expression (33/70x100=47.1\%; Fig. 1A), and 37 demonstrated weak expression $(37 / 70 \times 100=52.9 \%$; Fig. 1B). In the majority of the PCHNT and non-cancerous specimens, negative or weakly positive immunostaining of GRK6 in the cytoplasmic region was observed (Fig. 1C and D). GRK6 expression was significantly higher in carcinoma tissues compared with PCHNT and non-cancerous tissues $(\mathrm{P}<0.05$; Table I). However, 

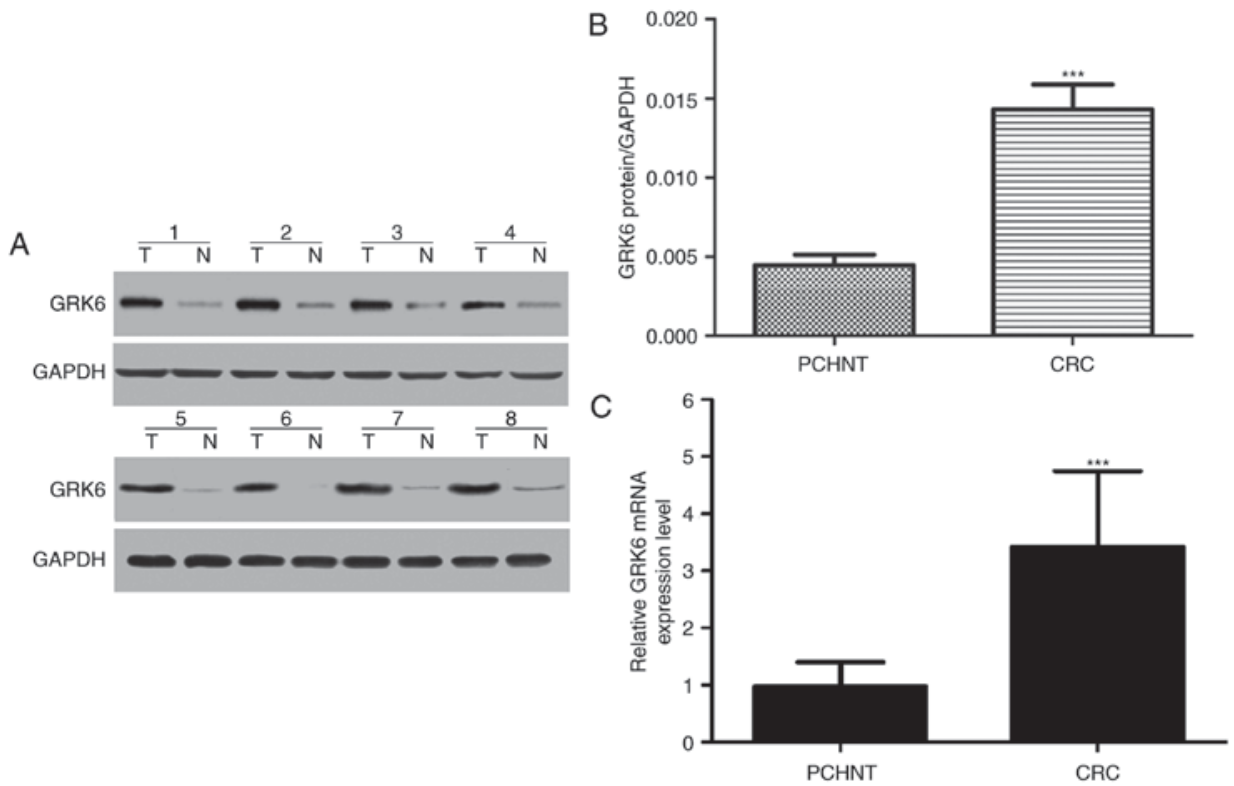

Figure 2. Expression of GRK6 was upregulated in CRC tissues. (A) Western blot analysis of eight representative paired samples of CRC tissues and PCHNTs. (B) Quantitative analysis of western blotting results of GRK6 expression in 19 CRC tissues and corresponding PCHNTs. (C) The expression levels of GRK6 mRNA in CRC tissues and PCHNTs were determined by reverse transcription-quantitative polymerase chain reaction and were normalized to the levels of GAPDH. ${ }^{* * *} \mathrm{P}<0.05$. CRC, colorectal carcinoma; GRK6, G protein-coupled receptor kinase 6; PCHNT, paracancerous histological normal tissue; T, tumor tissue; $\mathrm{N}$, non-tumor tissue.

there were no statistically significant differences in GRK6 expression between normal colorectal tissues and PCHNT specimens $(\mathrm{P}=0.289)$.

The expression of GRK6 protein was examined by western blotting in 19 pairs of randomly selected specimens of CRC tissues and their matched normal colorectal tissues. The representative results of western blotting in 8 cases are presented in Fig. 2A. The expression levels of GRK6 protein were markedly increased in tumor tissues compared with adjacent non-cancerous tissues (Fig. 2B). Therefore, GRK6 may be a potential candidate for the regulation of CRC initiation and progression.

The aforementioned results were further confirmed by RT-qPCR analysis. GRK6 mRNA expression was examined in 19 CRC tissues and corresponding PCHNT specimens, which were randomly selected. GRK6 expression was significantly upregulated in samples of CRC tissues compared with PCHNT specimens ( $\mathrm{P}<0.05$; Fig. 2C).

Association between GRK6 expression and clinicopathological factors in patients with $C R C$. The association between GRK6 expression and clinicopathological factors in patients with CRC is summarized in Table II. The overexpression of GRK6 was significantly associated with histological differentiation, lymph node metastasis, venous invasion, depth of invasion, distant metastasis, and TNM stages ( $\mathrm{P}=0.001$, $\mathrm{P}=0.045, \mathrm{P}=0.009, \mathrm{P}=0.026, \mathrm{P}<0.0001, \mathrm{P}=0.020$, respectively) in patients with CRC. However, no significant associations were observed between GRK6 expression and age, sex, tumor size and growth patterns in patients with CRC. In addition, no significant association was observed between the levels of preoperative carcinoembryonic antigen (CEA) $(\mathrm{P}=0.705)$, CA19-9 $(\mathrm{P}=0.443)$ and GRK6 expression. The results demonstrated that GRK6 expression in CRC specimens was positively associated with TNM stage, which indicated that advanced TNM stages corresponded to increased GRK6 expression in CRC $\left(r_{s}=0.467, \mathrm{P}<0.01\right.$; Table III).

Association between GRK6 expression and survival rates in patients with $C R C$. The survival statuses of 83 patients with CRC were evaluated by Kaplan-Meier survival curves and the log-rank test at the end of clinical follow-up. Based on the results of immunohistochemical staining for GRK6 expression, patients with CRC were divided into two groups, namely, the patient group with low GRK6 expression (- to + ) and the patient group with high GRK6 expression (++ to +++). There were 50 patients in the group with low levels of GRK6 expression, of which 11 succumbed to disease. The 5-year overall survival rate was $78 \%$. There were 33 patients with high levels of GRK6 expression, of which 22 succumbed to disease. The 5 -year overall survival rate was $33.3 \%$. Therefore, the overall survival of patients with CRC and low GRK6 expression was significantly longer compared with patients with CRC with high GRK6 expression (Fig. 3A).

Furthermore, the survival rates of patients based on GRK6 positivity were analyzed by separating the patients into two groups based on the stage of disease: I-II and III-IV. In patients with stage I-II disease, there were 36 patients with low GRK6 expression (- to +), of which 6 succumbed to disease, and there were 17 patients with high GRK6 expression (++ to +++$)$, of which 7 succumbed to disease. In patients with stage III-IV disease there were 14 patients with low GRK6 expression, of which 5 succumbed to disease. There were 16 patients in the high GRK6 expression group, of which 15 succumbed to disease. The overall survival of the group with high GRK6 expression was significantly shorter compared with the group with low GRK6 expression, irrespective of the differences in the stage of disease (Fig. 3B and C). 
Table II. Associations between GRK6 protein expression and clinicopathological parameters in colorectal cancer tissues.

\begin{tabular}{lcc}
\hline & \multicolumn{2}{c}{ GRK6 expression } \\
Clinical & Total High moderate Absent & \\
parameters & P-value
\end{tabular}

Sex

Sex

Male

Female

Age (years)

$$
\geq 50
$$$$
\leq 50
$$

$\begin{array}{lll}44 & 7 & 31 \\ 39 & 4 & 28\end{array}$

Tumor size (cm)

$$
\begin{aligned}
& >3 \\
& \leq 3
\end{aligned}
$$

Growth pattern

Expanding type Infiltration type Ulcerative type

Differentiation

Well/moderate

Poor

Lymph node invasion

Negative
Positive

Venous invasion

Negative

Positive

Depth of invasion

$\mathrm{T} 1 / \mathrm{T} 2$

T3/T4

Distant metastasis

M0
M1

TNM stage

$$
\text { I/II }
$$

III/IV

CEA level

(ng ml-1)

$\begin{array}{lllll}>5 & 44 & 5 & 33 & 6 \\ \leq 5 & 39 & 6 & 26 & 7\end{array}$

CA19-9 level $\left(\mathrm{U} \mathrm{ml}^{-1}\right)$

\begin{tabular}{lllll}
$>37$ & 23 & 4 & 14 & 5 \\
$\leq 37$ & 60 & 7 & 45 & 8 \\
\hline
\end{tabular}

${ }^{\mathrm{a}} \mathrm{P}<0.05$; CA19-9, cancer antigen 19-9; CEA, carcinoembryonic antigen; GRK6, G protein-coupled receptor kinase 6; TNM, tumor-node-metastasis.

0.133

$0.001^{\mathrm{a}}$

$0.045^{\mathrm{a}}$

$0.009^{\mathrm{a}}$

$0.026^{\mathrm{a}}$

$<0.0001^{\mathrm{a}}$

$0.020^{\mathrm{a}}$

0.705

0.443
Table III. Association between GRK6 expression and TNM stage in colorectal carcinoma.

\begin{tabular}{lrrrrrrr}
\hline & \multicolumn{3}{c}{ GRK6 expression } & & & \\
\cline { 2 - 4 } TNM stage & - & + & ++ & +++ & Total & $\mathrm{r}_{\mathrm{s}}$ & P-value \\
\hline I & 5 & 8 & 3 & 0 & 16 & & \\
II & 3 & 20 & 11 & 3 & 37 & & \\
III & 5 & 7 & 7 & 3 & 22 & & \\
IV & 0 & 2 & 1 & 5 & 8 & 0.459 & $<0.01^{\mathrm{a}}$ \\
Total & 13 & 37 & 22 & 11 & 83 & & \\
\hline
\end{tabular}

aPearson's $\chi^{2}$ test; $r_{s}$, Spearman rank-order coefficient; GRK6, G protein-coupled receptor kinase 6; TNM, tumor-node-metastasis.

Figure 3. Survival curves of patients with CRC and different expression levels of GRK6 as assessed by Kaplan-Meier method and the log-rank test. (A) The overall survival rate in patients with high expression levels of GRK6 was significantly lower compared with patients with low expression levels of GRK6. (B) The overall survival rate in patients with stage I-II CRC with high GRK6 expression was significantly lower compared with corresponding patients with low expression levels of GRK6 $(\mathrm{P}=0.029)$. (C) The overall survival rate in patients with stage III-IV CRC with high expression levels of GRK6 was significantly lower compared with corresponding patients with low expression levels of GRK6 ( $\mathrm{P}<0.0001)$. CRC, colorectal carcinoma; GRK6, G protein-coupled receptor kinase 6; TNM, tumor-node-metastasis. 
Table IV. Cox proportional hazards model analysis of prognostic factors.

\begin{tabular}{lccccrr}
\hline & \multicolumn{2}{c}{ Characteristics } & & & \\
\cline { 2 - 3 } Factors & Unfavorable & Favorable & & Hazard ratio & $95 \%$ CI & P-value \\
\hline TNM stage & III/IV & I/II & & 3.195 & $1.691-6.250$ & $<0.001^{\text {a }}$ \\
Lymph node & Present & None & & 2.317 & $1.210-4.976$ & $0.023^{\text {a }}$ \\
Tumor invasion & T3/T4 & T1/T2 & & 2.660 & $1.413-5.199$ & $0.021^{\text {a }}$ \\
Histological differentiation & Poor & Well/moderate & 2.530 & $1.752-7.136$ & $<0.001^{\text {a }}$ \\
GRK6 expression & Positive & Negative/weak & 2.020 & $1.052-3.889$ & $0.003^{\text {a }}$ \\
CEA level $\left(\mu \mathrm{g} \mathrm{l}^{-1}\right)$ & $\geq 5$ & $<5$ & & 2.114 & $1.786-3.136$ & $0.001^{\text {a }}$ \\
CA19-9 level $\left(\mu \mathrm{g} \mathrm{l}^{-1}\right)$ & $\geq 37$ & $<37$ & & 2.977 & $1.236-3.929$ & $0.034^{\text {a }}$ \\
\hline
\end{tabular}

${ }^{a} \mathrm{P}<0.05$; CA19-9, cancer antigen 19-9; CEA, carcinoembryonic antigen; CI, confidence interval; GRK6, G protein-coupled receptor kinase 6; TNM, tumor-node-metastasis.

Prognostic value of GRK6 expression in patients with CRC. To evaluate the independent prognostic value of GRK6 expression on overall survival in patients with CRC, multivariate analysis was performed to evaluate the prognostic factors in the present study cohort using a Cox proportional hazard model (Table IV). In these patients, TNM stages, lymph node metastases, histological differentiation, tumor invasion, GRK6 expression, and the levels of CEA and CA19-9 were associated with poor prognosis $(\mathrm{P}<0.001, \mathrm{P}=0.023, \mathrm{P}<0.001, \mathrm{P}=0.021$, $\mathrm{P}=0.003, \mathrm{P}=0.001, \mathrm{P}=0.034$, respectively).

\section{Discussion}

$\mathrm{CRC}$ is one of the leading causes of cancer-associated mortalities worldwide. Despite numerous advances in diagnostic methods, combination chemotherapy and radiation therapy, the prognosis and quality of life for patients with CRC remains poor (26). Due to the frequent failures of conventional treatment strategies, many molecular biomarkers have been characterized for the development of novel anticancer therapies, including targeted drugs $(7,27)$. To date, prognostic treatment strategies largely depend on clinical staging and histopathological criteria. However, the current staging classifications do not accurately predict patient outcomes (8). Therefore, it is critical to investigate biological markers that could appropriately determine the risk of poor prognoses in patients.

GRKs are a versatile family of kinases, which contribute to important functions in the desensitization of $\mathrm{G}$ protein-coupled receptor homologous. GRKs promote the receptor-arrestin interaction and the uncoupling of the receptor from its $G$ protein by phosphorylating specific serine and threonine residues in the cytoplasmic domains of the activated receptor $(10,11)$. GRK6 is the most recently identified member of the family of GRKs (10). Recent studies demonstrated that the overexpression of GRK6 exerts an important role in the process of transduction of pain signals $(11,28-31)$. Previous studies also revealed that endogenous GRK6 molecules contribute to the desensitization of M3 muscarinic acetylcholine in the human SH-SY5Y neuroblastoma cell line (32). Furthermore, the 'silencing' of GRK6 in myeloma cells reduced the levels of myeloid cell leukemia 1 and suppressed the phosphorylation of signal transducer and activator of transcription 3 (STST3), thereby causing a tumor-inhibitory effect (16). Additionally, Chen et al (33) demonstrated that GRK6 serves critical roles in cell adhesion and migration of three cancer cell lines (pC3, MB231 and HeLa cells) (33). Additionally, GRK6 provides a scaffold for signaling molecules to regulate cell adhesion and organization of cytoskeleton by interacting with $G$ protein-coupled receptor kinase interacting ArfGAP 1 and indirectly trans-activating epidermal growth factor receptor, which in turn affects the migration and invasion of cancer cells (14). GRK6 may affect the migration and invasion of cancer cells through secondary messengers, including cAMP and calmodulin (34). Based on these studies, it may be inferred that GRK6 contributes an important role in angiogenesis, tumor progression, metastasis and cell proliferation. Therefore, its was proposed that GRK6 expression in $\mathrm{CRC}$ tissues may predict the prognoses of patients with this disease.

Immunohistochemical staining was used to detect GRK6 protein expression in CRC tissues. Notably, GRK6 expression in CRC tissues was higher compared with normal colorectal tissues. This observation was further confirmed by RT-qPCR and western blot analysis. The association between GRK6 expression and clinicopathological features in CRC was further examined, including the prognosis of patients. GRK6 expression was positively associated with histological differentiation, venous invasion, depth of invasion, lymph node metastasis, distant metastasis, and TNM staging in CRC. Therefore, high GRK6 expression may be a potential diagnostic biomarker for specific subtypes of CRC. In survival analysis as assessed by Kaplan-Meier method, the overall 5-year survival of patients with negative or weakly positive GRK6 expression was significantly longer compared with patients with strongly positive GRK6 expression. Additionally, it was observed that the survival time of patients with stage I-II CRC were significantly longer compared with the survival times of patients with stage III-IV CRC $(\mathrm{P}<0.05)$. Furthermore, Spearman's rank correlation analysis indicated that the more advanced TNM stages corresponded to higher GRK6 expression 
levels in CRC. Previous studies have revealed that GRK6 expression contributes to the progression of several types of cancer $(11,16,18,28-31)$.

Despite these diverse studies, the precise functions and the mechanistic actions of GRK6 have not been defined completely. In univariate survival analysis, GRK6 expression was significantly associated with prognosis, and this prognostic value was retained in multivariate survival analysis. This indicates that high GRK6 expression may predict poor prognosis in patients with CRC. Furthermore, the overexpression of GRK6 was correlated with poor differentiation, venous invasion, deep tissue invasion, distant metastasis, lymph node metastasis and high TNM grades $(\mathrm{P}<0.05)$. This also indicates that GRK6 contributes an important role in the invasion, progression and metastasis of CRC. The results from the present study reveal that increased GRK6 expression may help to identify patients with CRC, who have poor prognosis. However, the precise mechanism of action of GRK6 in CRC and other tumors remains unclear. It is worthwhile to explore further functional investigations of the effect of GRK6 expression, and provide further evidence, which yields molecular targets for diagnosing and treating CRC and other types of tumors.

In conclusion, the present study has provided new insights into the role of GRK6 expression in the development of CRC. The results of the present study support the interpretation that GRK6 is a tumor-promoting factor in CRC, and therefore it may serve as an independent biomarker for poor survival in patients with CRC. Therefore, high GRK6 expression may identify high-risk patients and be a potential novel therapeutic target in CRC.

\section{Acknowledgements}

Not applicable

\section{Funding}

No funding was received.

\section{Availability of data and materials}

All data generated or analyzed during this study are included in this published article.

\section{Authors' contributions}

LM and RT had the concept for and designed the study. RT and QL acquired, analysed and interpreted the data. XG analysed and interpreted the data. RT, QL and XG drafted the manuscript. RT and QL critically revised the manuscript.

\section{Ethics approval and consent to participate}

The present study was approved by the Ethics Committee of the Affiliated Hospital of Nantong University (Nantong, China). All experiments were performed in accordance with the approved guidelines of the Affiliated Hospital of Nantong University and the 1964 Helsinki Declaration and its later amendments.

\section{Consent for publication}

Written informed consent was obtained from all participants prior to undergoing surgery.

\section{Competing interests}

The authors declare that they have no competing interests.

\section{References}

1. Cassidy J, Saltz L, Twelves C, Van Cutsem E, Hoff P, Kang Y, Saini JP, Gilberg F and Cunningham D: Efficacy of capecitabine versus 5-fluorouracil in colorectal and gastric cancers: A meta-analysis of individual data from 6171 patients. Ann Oncol 22: 2604-2609, 2011.

2. Chen W, Zheng R, Zeng H and Zhang S: The updated incidences and mortalities of major cancers in China, 2011. Chin J Cancer 34: 502-507, 2015.

3. Sugarbaker PH: Second-look surgery for colorectal cancer: Revised selection factors and new treatment options for greater success. Int J Surg Oncol 2011: 915078, 2011.

4. Liu QZ, Gao XH, Chang WJ, Gong HF, Fu CG, Zhang W and Cao GW: Expression of ITGB1 predicts prognosis in colorectal cancer: A large prospective study based on tissue microarray. Int J Clin Exp Pathol 8: 12802-12810, 2015.

5. Uhry Z, Belot A, Colonna M, Bossard N, Rogel A, Iwaz J, Mitton N, Grosclaude P and Remontet L: National cancer incidence is estimated using the incidence/mortality ratio in countries with local incidence data: Is this estimation correct? Cancer Epidemiol 37: 270-277, 2013.

6. Alsop K, Mead L, Smith LD, Royce SG, Tesoriero AA, Young JP, Haydon A, Grubb G, Giles GG, Jenkins MA, et al: Low somatic $\mathrm{K}$-ras mutation frequency in colorectal cancer diagnosed under the age of 45 years. Eur J Cancer 42: 1357-1361, 2006.

7. Brink M, de Goeij AF, Weijenberg MP, Roemen GM, Lentjes MH, Pachen MM, Smits KM, de Bruïne AP, Goldbohm RA and van den Brandt PA: K-ras oncogene mutations in sporadic colorectal cancer in the netherlands cohort study. Carcinogenesis 24: 703-710, 2003.

8. Jimi S, Yasui T, Hotokezaka M, Shimada K, Shinagawa Y, Shiozaki H, Tsutsumi N and Takeda S: Clinical features and prognostic factors of bone metastases from colorectal cancer. Surg Today 43: 751-756, 2013.

9. Lan YT, Chang SC, Yang SH, Lin CC, Wang HS, Jiang JK, Chen WS, Lin TC, Chiou SH and Lin JK: Comparison of clinicopathological characteristics and prognosis between early and late recurrence after curative surgery for colorectal cancer. Am J Surg 207: 922-930, 2014.

10. Vroon A, Heijnen CJ and Kavelaars A: GRKs and arrestins: Regulators of migration and inflammation. J Leukoc Biol 80: 1214-1221, 2006

11. Raghuwanshi SK, Smith N, Rivers EJ, Thomas AJ, Sutton N, Hu Y, Mukhopadhyay S, Chen XL, Leung T and Richardson RM: $G$ protein-coupled receptor kinase 6 deficiency promotes angiogenesis, tumor progression and metastasis. J Immunol 190: 5329-5336, 2013.

12. Dorn GW II: GRK mythology: G-protein receptor kinases in cardiovascular disease. J Mol Med 87: 455-463, 2009.

13. Metaye $T$, Gibelin $H$, Perdrisot $R$ and Kraimps JL: Pathophysiological roles of G-protein-coupled receptor kinases. Cell Signal 17: 917-928, 2005.

14. Premont RT, Claing A, Vitale N, Freeman JL, Pitcher JA, Patton WA, Moss J, Vaughan M and Lefkowitz RJ: Beta2-Adrenergic receptor regulation by GIT1, a G protein-coupled receptor kinase-associated ADP ribosylation factor GTPase-activating protein. Proc Natl Acad Sci USA 95: 14082-14087, 1998.

15. Ahmed MR, Berthet A, Bychkov E, Porras G, Li Q, Bioulac BH, Carl YT, Bloch B, Kook S, Aubert I, et al: Lentiviral overexpression of GRK6 alleviates L-dopa-induced dyskinesia in experimental Parkinson's disease. Sci Transl Med 2: 28ra28, 2010.

16. Tiedemann RE, Zhu YX, Schmidt J, Yin H, Shi CX, Que Q, Basu G, Azorsa D, Perkins LM, Braggio E, et al: Kinome-wide RNAi studies in human multiple myeloma identify vulnerable kinase targets, including a lymphoid-restricted kinase, GRK6. Blood 115: 1594-1604, 2010. 
17. Yao S, Zhong L, Liu J, Feng J, Bian T, Zhang Q, Chen J, Lv X, Chen J and Liu Y: Prognostic value of decreased GRK6 expression in lung adenocarcinoma. J Cancer Res Clin Oncol 142: $2541-2549,2016$

18. Li YP: GRK6 expression in patients with hepatocellular carcinoma. Asian Pac J Trop Med 6: 220-223, 2013.

19. Yuan L, Zhang H, Liu J, Rubin JB, Cho YJ, Shu HK, Schniederjan $M$ and MacDonald TJ: Growth factor receptor-Src-mediated suppression of GRK6 dysregulates CXCR4 signaling and promotes medulloblastoma migration. Mol Cancer 12: 18, 2013

20. Altman DG, McShane LM, Sauerbrei W and Taube SE: Reporting recommendations for tumor marker prognostic studies (REMARK): Explanation and elaboration. PLoS Med 9: e1001216, 2012.

21. Sobin LH and Fleming ID: TNM classification of malignant tumors, fifth edition (1997). Union internationale contre le cancer and the american joint committee on cancer. Cancer 80 : 1803-1804, 1997

22. Gupta S, Provenzale D, Regenbogen SE, Hampel H, Slavin TP Jr, Hall MJ, Llor X, Chung DC, Ahnen DJ, Bray T, et al: NCCN guidelines insights: Genetic/Familial high-risk assessment: Colorectal, 2008. J Natl Compr Canc Netw 15: 9-20, 2007.

23. Li Q, Zhi X, Zhou J, Tao R, Zhang J, Chen P, Røe OD, Sun L and Ma L: Circulating tumor cells as a prognostic and predictive marker in gastrointestinal stromal tumors: A prospective study. Oncotarget 7: 36645-36654, 2016.

24. Livak KJ and Schmittgen TD: Analysis of relative gene expression data using real-time quantitative PCR and the 2(-Delta Delta C(T)) method. Methods 25: 402-408, 2001.

25. Shi R, Wang L, Wang T, Xu J, Wang F and Xu M: NEDD9 overexpression correlates with the progression and prognosis in gastric carcinoma. Med Oncol 31: 852, 2014

26. Tian Y, Xu T, Huang J, Zhang L, Xu S, Xiong B, Wang Y and Tang H: Tissue metabonomic phenotyping for diagnosis and prognosis of human colorectal cancer. Sci Rep 6: 20790, 2016.
27. Ikeda K, Kojima M, Saito N, Sakuyama N, Koushi K, Watanabe T, Sugihara K, Akimoto T, Ito M and Ochiai A: Current status of the histopathological assessment, diagnosis and reporting of colorectal neuroendocrine tumors: A web survey from the japanese society for cancer of colon and rectum. Pathol Int 66: 94-101, 2016.

28. Shitara K, Mizota A, Yatabe Y, Kondo C, Nomura M, Yokota T, Takahari D, Ura T and Muro K: Lapatinib plus trastuzumab for a patient with heavily pre-treated gastric cancer that progressed after trastuzumab. Jan J Clin Oncol 41: 663-665, 2011.

29. Chua TC and Merrett ND: Clinicopathologic factors associated with HER2-positive gastric cancer and its impact on survival outcomes-a systematic review. Int J Cancer 130: 2845-2856, 2012.

30. Benovic JL and Gomez J: Molecular cloning and expression of GRK6. A new member of the G protein-coupled receptor kinase family. J Biol Chem 268: 19521-19527, 1993.

31. Zhou Y, Li RJ, Li M, Liu X, Zhu HY, Ju Z, Miao X and Xu GY: Overexpression of GRK6 attenuates neuropathic pain via suppression of CXCR2 in rat dorsal root ganglion. Mol Pain 12: 1744806916646381,2016

32. Willets JM, Challiss RA and Nahorski SR: Endogenous G protein-coupled receptor kinase 6 Regulates M3 muscarinic acetylcholine receptor phosphorylation and desensitization in human SH-SY5Y neuroblastoma cells. J Biol Chem 277: 15523-15529, 2002.

33. Chen Y, Lu B, Yang Q, Fearns C, Yates JR III and Lee JD: Combined integrin phosphoproteomic analyses and small interfering RNA-based functional screening identify key regulators for cancer cell adhesion and migration. Cancer Res 69: 3713-3720, 2009

34. Ribas C, Penela P, Murga C, Salcedo A, García-Hoz C, Jurado-Pueyo M, Aymerich I and Mayor F Jr: The G protein-coupled receptor kinase (GRK) interactome: Role of GRKs in GPCR regulation and signaling. Biochim Biophys Acta 1768: 913-922, 2007. 